\title{
Liquid Hydrogen for Automotive Application Next Generation Fuel for FC and ICE Vehicles
}

\author{
Gerd ARNOLD* and Joachim WOLF**
}

\begin{abstract}
Synopsis: Recent progress in fuel cell technology development for automotive application urges the need of an appropriate fuel for the next generation of cars. There has a basic consensus emerged within the engineering community and the environmentalists that hydrogen as an energy carrier should be the successor of fossil fuel derivates for both the new fuel cell vehicles as well as for the conventional internal combustion engines. On a gravimetric basis, hydrogen is an excellent energy carrier and when used in a fuel cell the only tailpipe emission is water. As the hydrogen gas density is very poor at ambient conditions, liquid hydrogen has become of great interest for automotive application. Consequently, a new infrastructure should provide liquid hydrogen at the pump for refuelling purposes. In regard of economically viable gas transportation and bulk storage at the refuelling station there are significant advantages using liquid hydrogen. A future scenario is likely to be realized by a liquid hydrogen supply system dispensing the gas in liquid and compressed form at the refuelling station.
\end{abstract}

Keywords: fuel cell vehicles, hydrogen refuelling, hydrogen transportation, liquid hydrogen, compressed hydrogen

\section{Introduction}

Since mankind is facing the beginning of the "end of cheap oil era" there is common understanding in the scientific community and the energy industry to search for a new energy carrier. Serious down-selection processes in different nations turned out that hydrogen will be the ultimate choice. Hydrogen can be used as a secondary energy source in automotive applications without emitting any carbon dioxide using new technologies like PEM (Proton Exchange Membrane) fuel cells to generate electricity for an electric drive as well as a direct fuel for internal combustion engines.

One of the reasons giving the preference to hydrogen is seen in the multi feedstock versatility for its generation. As there is practically no hydrogen gas abundant in nature, the only possibility is to release it from its chemical binding to other atoms. Amongst others, there are basically two ways of hydrogen production: splitting hydrocarbons or splitting water. Hydrocarbons are either decomposed by steam reforming or fermentation. Water splitting can be achieved directly under high temperatures or by using electricity (a process known as electrolysis). Burning coal under water vapour is another way of producing hydrogen from water.

Well-to-wheel-studies ${ }^{1-3)}$ have shown that it does make sense to convert fossil fuels like natural gas first into

\footnotetext{
Received May 31, 2005

* Adam Opel AG, IPC MK-01, D-65423 Rüsselsheim, Germany

E-mail: gerd.arnold@de.opel.com

** Linde AG, Seitnerstr. 70, D-82049 Hoellriegelskreuth, Germany

E-mail: joachim.wolf@linde-gas.com
}

hydrogen; and using it afterwards in fuel cell vehicles. In a final scenario, when fossil fuels will get seriously expensive and are probably banned because of the greenhouse problem, regenerative primary energies will come into play either forced by commercial reasons or dictated for environmental protection.

Regarding energy content, weight and volume of the newly proposed hydrogen fuel there are obviously some differences compared to the commonly used ones. The most outstanding feature is the low weight of hydrogen in regard to its energy content, which is shown in Fig. 1.

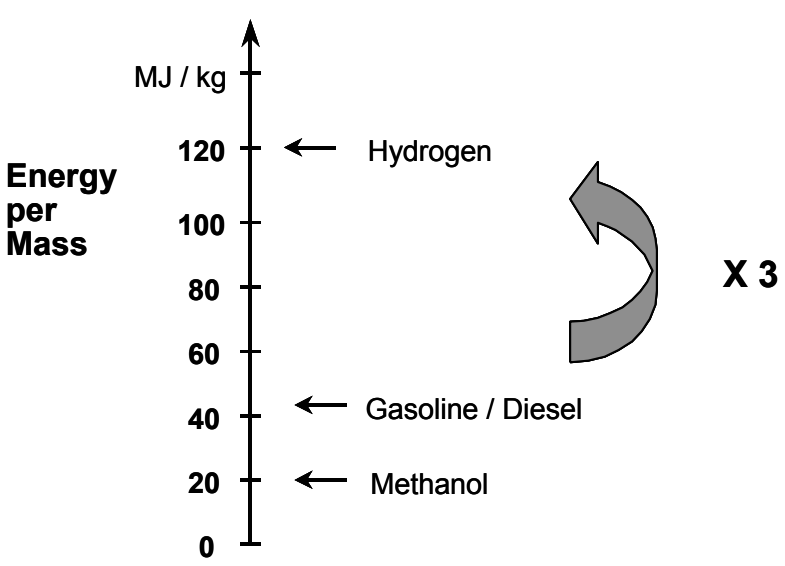

Fig. 1 Gravimetric energy density of certain fuels for mobile application. Hydrogen gas contains $120 \mathrm{MJ}$ of energy per $\mathrm{kg}$ which is three times higher than gasoline and diesel fuels. Compared to methanol the advantage is six fold. 


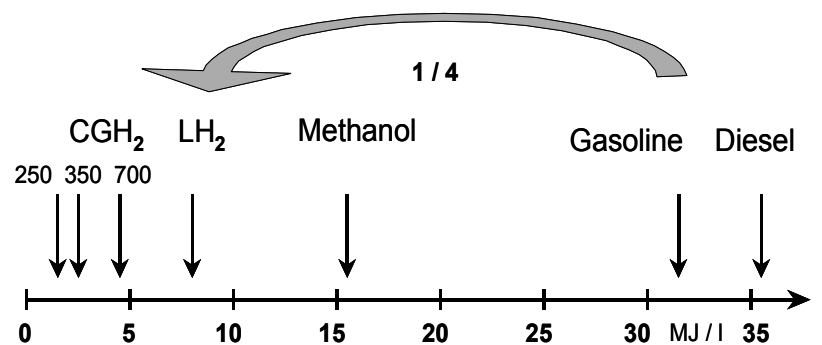

Fig. 2 Volumetric Energy Density of hydrogen under different pressures (250 bars, 350 bars, 700 bars) and as a liquid. Compared to the hydrocarbon fuels like gasoline and diesel the density is rather low. Even liquid hydrogen can only achieve a quarter of the value of gasoline. Consequently, hydrogen tanks for automotive application will occupy much more space than the currently used tanks for liquid hydrocarbons.

Hydrogen contains $120 \mathrm{MJ}$ per $\mathrm{kg}$ which is three times more than gasoline and diesel. Compared to methanol the advantage is six fold.

In contrary to the very impressive gravimetric density of hydrogen, its volumetric energy density is rather low. The volumetric density of hydrogen depends on the state of aggregation. Even a pressure up to 700 bars is still not sufficient to cope with the excellent properties of hydrocarbons like gasoline and diesel. Only liquid hydrogen can achieve a reasonable value which is still only a quarter of the value of gasoline, Fig. 2. Consequently, hydrogen tanks for automotive application will occupy much more space than the currently used tanks for liquid hydrocarbons.

\section{FC Vehicle}

In the early days of 1966, when fuel cell systems had been developed for space application, GM already created a prototype vehicle which was powered by electricity generated by a fuel cell, Fig. 3. With the volumetric density problem in mind, the engineers decided in those days to install cryo tanks, one for liquid hydrogen and one for liquid oxygen.

GM's latest roadworthy FC vehicle, the HydroGen3, was launched in 2002. A 200 cell PEM fuel cell stack of $94 \mathrm{~kW}$ output powers an electric motor of $60 \mathrm{~kW}$, propelling the car to a top speed of $160 \mathrm{~km} / \mathrm{h}$. The vehicle is equipped with a cryo tank for liquid hydrogen with a maximum content of $4.6 \mathrm{~kg}$. The range in an EDC cycle is around 400 $\mathrm{km}$. The packaging of the system components compares well to common passenger cars in regard to interior and trunk space, see Fig. 4 and Fig. 5.

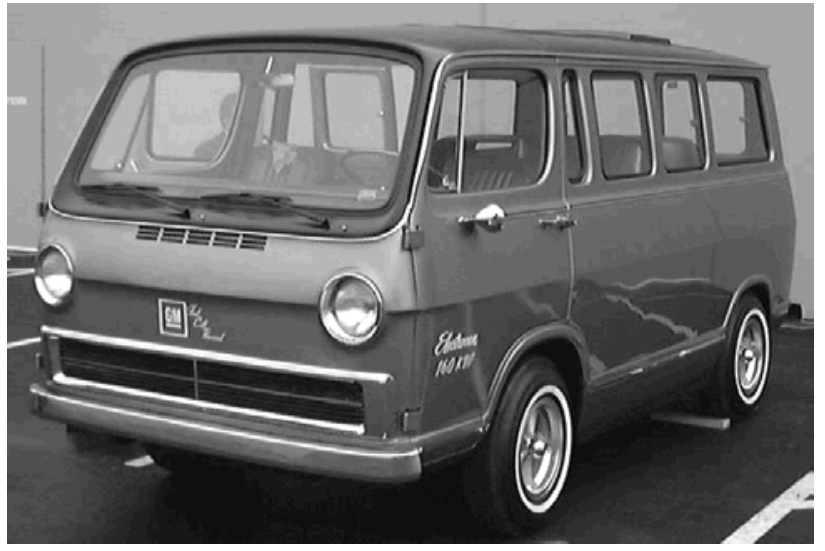

Fig. 3 First GM Fuel Cell Vehicle (Electro Van, 1966). The vehicle was already equipped with cryo tanks for liquid hydrogen as well as for liquid oxygen.

In several contests around the world the GM vehicle has demonstrated that liquid hydrogen is a valid option for automotive application. Similar positive experiences are reported from BMW's vehicles of the Seven Series"), which are running on liquid hydrogen using a larger cryo tank $\left(\sim 10 \mathrm{~kg} \mathrm{H}_{2}\right)$ and are powered by internal combustion engines.

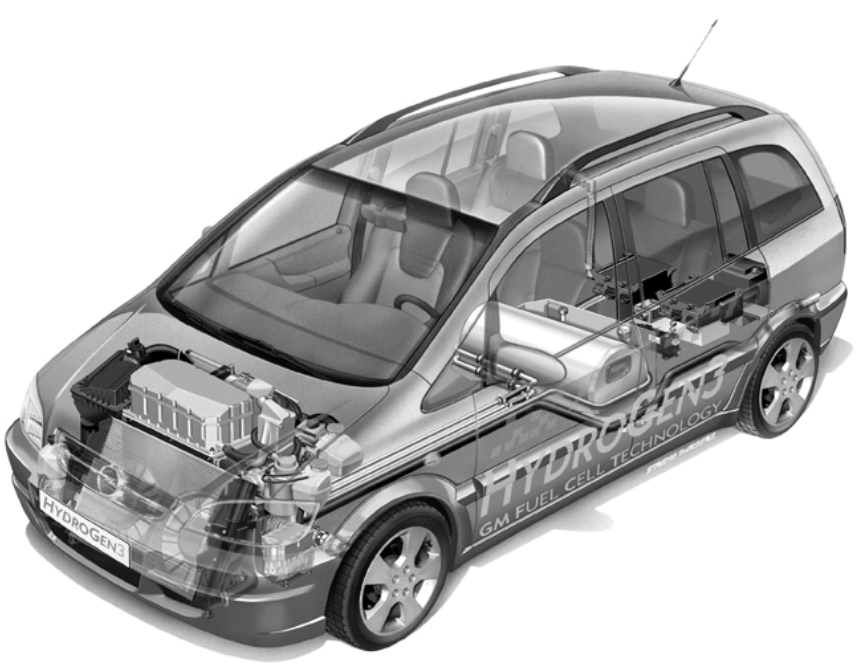

Fig. 4 GM's latest roadworthy HydroGen3 fuel cell vehicle which was launched in 2002. A 200 cell PEM fuel cell stack of $94 \mathrm{~kW}$ output is powering an electric motor of $60 \mathrm{~kW}$, which is good for top speed of $160 \mathrm{~km} / \mathrm{h}$. The vehicle is equipped with a cryo tank for liquid hydrogen with a maximal content of $4.6 \mathrm{~kg}$. The range in EDC cycle is around $400 \mathrm{~km}$. 


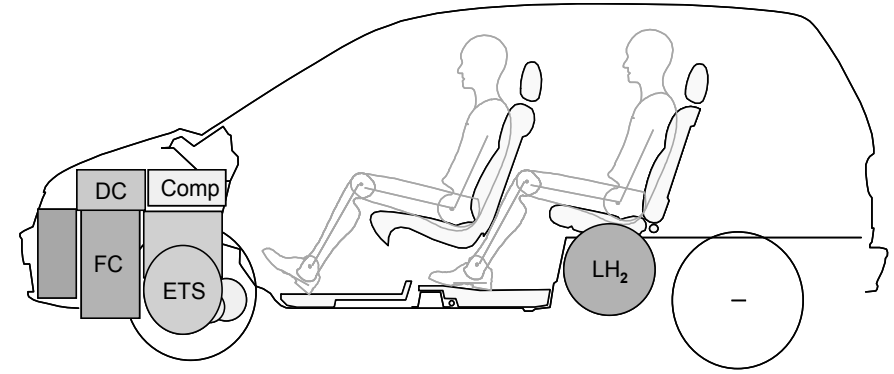

Fig. 5 FC vehicle with liquid hydrogen tank $\left(\mathrm{LH}_{2}\right)$ under second seat row. Located in the front engine bay are fuel cell (FC), DC/DC converter (DC), air compressor (Comp) and electric traction system (ETS).

\section{Liquid Hydrogen Tank}

At ambient pressure, hydrogen is a liquid with a boiling point at $20 \mathrm{~K}$. To maintain the liquid condition at this exceptional low temperature, it is required to keep heat intrusion on lowest possible levels. Cryo tanks with evacuated double walled containers and multilayer foil insulations in between have to be used.

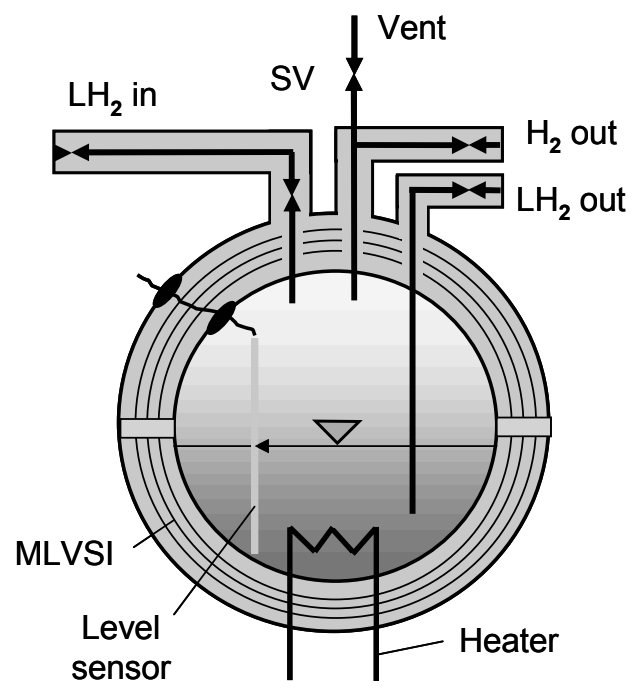

Fig. 6 Principle of liquid hydrogen cryo containers for automotive application. In addition to the vacuum, a multilayer foil insulation (MLVSI) in between the double walls is necessary to reduce the heat intrusion by radiation. The inner container needs to be fixed to the outer container solidly but avoiding any considerable heat transfer through the suspensions. A double-walled insulated liquid hydrogen filling pipe has to be routed from the filling port through the insulation to the inner tank. For safety reasons, a safety valve and a vent line to the outside is mandatory for cryogenic containers. Hydrogen take out in gaseous as well as a liquid form is controlled by cryogenic valves. For in-tank pressure control, an electrical heating device in combination with a pressure relief valve is advisable. The filling level is measured by an electrical level indicator.
The low value of the heat of evaporation $(31.5 \mathrm{~kJ} / l)$ is absolutely crucial for the successful storage of liquid hydrogen. The principle of liquid hydrogen cryo containers for automotive applications is shown in Fig. 6. The basic design is similar to cryo containers used in academia for storing Helium. As usual, the inner container needs to be fixed to the outer container avoiding any considerable heat transfer through the suspensions. The tough conditions during vehicle road driving causes an additional challenge to this design feature.

A double-walled insulated liquid hydrogen filling pipe has to be routed from the filling port through the insulation to the inner tank. Hydrogen take out in gaseous form as well as in liquid form is controlled by cryogenic valves. For safety reasons, a safety valve and a vent line to the outside is needed for cryogenic containers. For in-tank pressure control, an electrical heating device in combination with a pressure relief valve is advisable. The filling level is measured by an electrical level indicator.

The most recent liquid hydrogen tank of GM's HydroGen3 vehicle is shown in Fig. 7. The in- and outlet fittings and the cryogenic valves are arranged aside the cylinder in a box. The cryogenic valves are pneumatically actuated. The entire tank system is designed to fit in the cavity of the former gasoline tank of the respective production car (Opel Zafira), see also Fig. 5. Driven by the given vehicle package envelope, a storage capacity of 4.6 $\mathrm{kg}$ could be achieved. The entire system weight including mounting brackets totals up to $90 \mathrm{~kg}$.

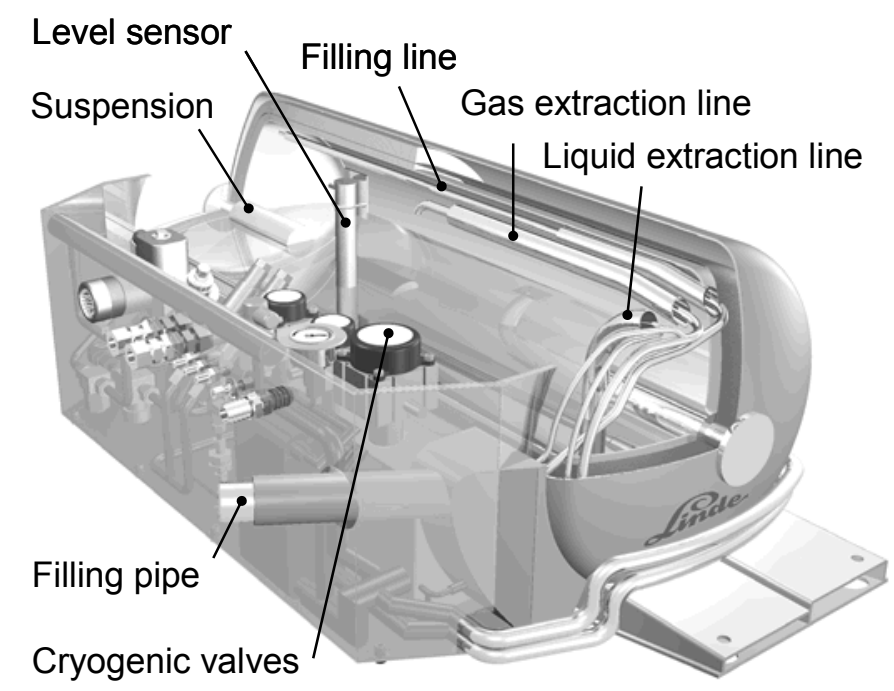

Fig. 7 Liquid Hydrogen tank of GM's HydroGen3 Fuel Cell Vehicle. The removed quarter section gives sight into the inner container. Hydrogen capacity is $4.6 \mathrm{~kg}$. Gross weight of the entire system is $90 \mathrm{~kg}$. 


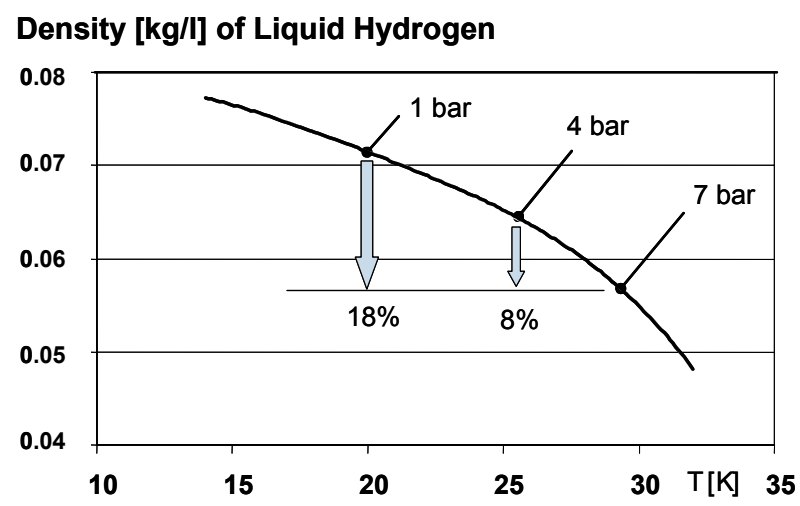

Fig. 8 Density of liquid hydrogen. There is only a small temperature range from $14 \mathrm{~K}$ to $33 \mathrm{~K}$ where liquid hydrogen exists. Within this range, its density drops by $60 \%$ from 0.77 $\mathrm{kg} / 1$ to $0.30 \mathrm{~kg} / \mathrm{l}$ when warmed up from $14 \mathrm{~K}$ to $33 \mathrm{~K}$.

When liquid hydrogen is stored in a closed cryo container, the unavoidable remaining heat entry ( 2 to 4 Watt) will raise the temperature and consequently the pressure. In GM/Opel's Zafira fuel cell vehicle, the in-tank pressure is used to provide the fuel cell system with hydrogen and is set to 4 bars during electrical power generation. The corresponding boiling or equilibrium temperature is $26 \mathrm{~K}$.

In parking mode under power-off conditions the tank pressure inevitably increases and finally the gas has to be vented to the outside. A "boil-off valve" is used to control a maximal allowed pressure level (7 bars) by releasing adequate amounts of "boil-off gas". The rate of the gas losses depends on the filling conditions and the quality of insulation, for 'state of the art' cryo containers the losses are around $2 \%-4 \%$ per day.

At 7 bars the equilibrium temperature reaches $29 \mathrm{~K}$. This temperature increase goes along with a remarkable density drop as shown in Fig. 8. To avoid an overfill situation, the related volume expansion has already to be taken into account during refuelling.

\section{Liquid Hydrogen Refuelling}

Refuelling liquid hydrogen basically means moving the liquid from one cryo container to another one. Consequently, pipes and hoses have to be insulated in the same way as cryo containers themselves, that means, a double-walled vacuum design combined with radiation shields has to be adopted. To establish a path for the liquid hydrogen, a dispenser must be matched with a refuelling nozzle. Before opening the valves on both ends, a purge process preferably done with Helium gas needs to be applied to the gap between the two valve faces. That is necessary to avoid any introduction of air into the tank system. Inside the dispenser there is an additional thermally insulated pipe which will be pushed forward after engagement and valve opening, see Fig. 9. This so called "cold finger" ensures an uninterrupted vacuum insulation over the entire pathway, which avoids firstly undesired heat introduction into the liquid hydrogen and secondly protects the joint against icing resulting from freezing moisture of the surrounding air. The nozzle and the dispenser are shown in Fig. 10.

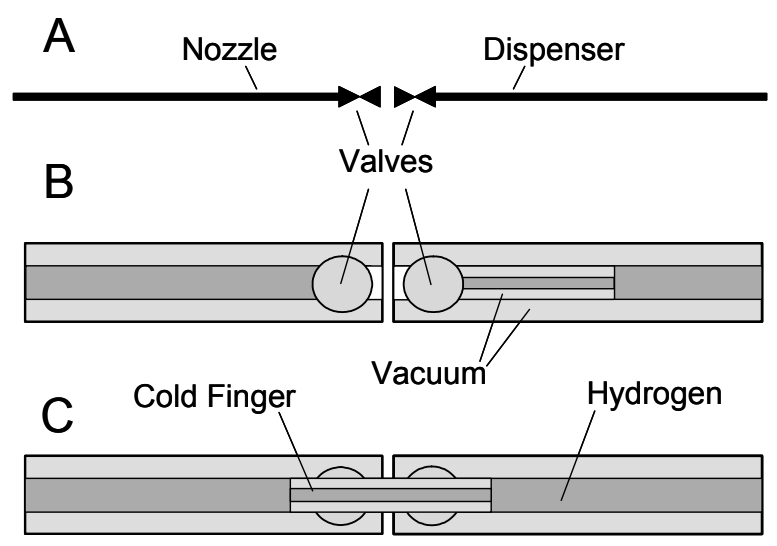

Fig. 9 Principle of liquid hydrogen refuelling coupling. Both lines are equipped with valves at their very ends (A). Double-walled insulation for the nozzle on the left hand side and the dispenser on the right hand side, valves are shown simplified as balls (B). Inside the dispenser there is an additional double-walled vacuum-insulated pipe which will be pushed forward after engagement and valve opening (C). This so called "cold finger" is a coaxial pipe design with a passage for the liquid as well as for gas return (not shown).

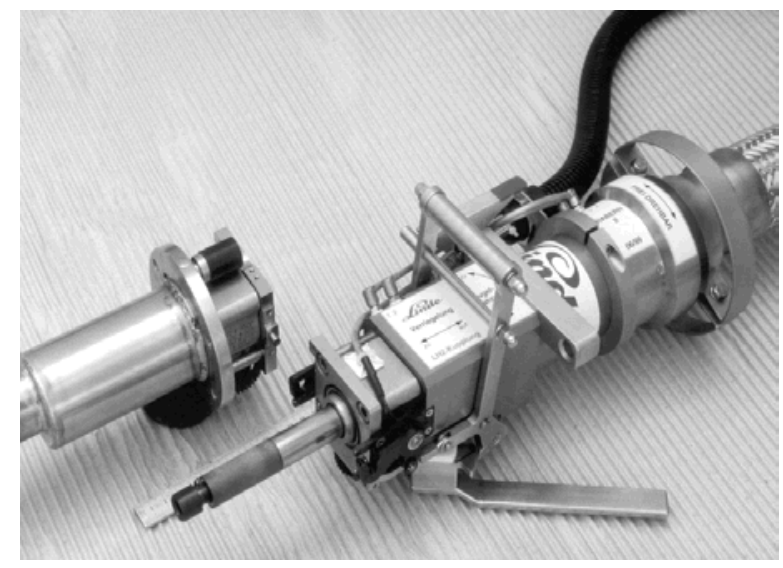

Fig. $10 \mathrm{LH}_{2}$ refuelling nozzle (left hand side) and dispenser. Both units are equipped with a ball valve at their very end, which are jointly opened and closed manually for dispense. After engagement (top handle) and valve opening (lower handle) a vacuum insulated pipe (sticks out of the front side of the dispenser for demonstration only) will be pushed forward pneumatically, controlled by the operator. 


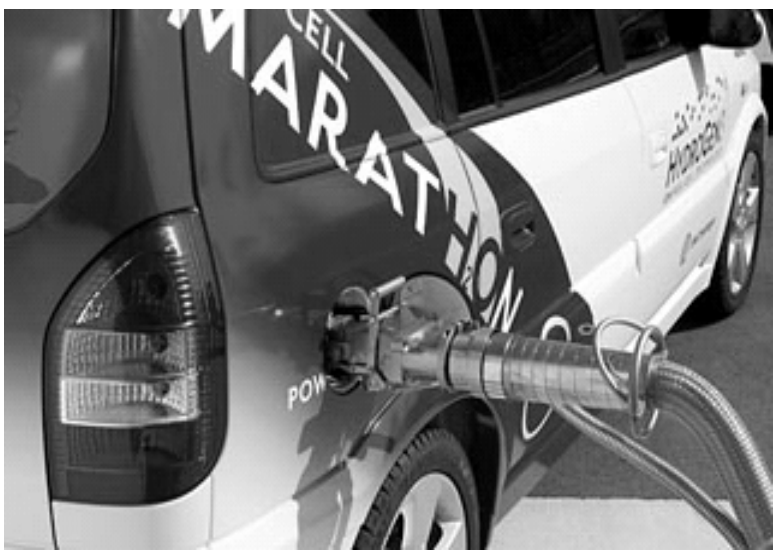

Fig. 11 Manually operated refuelling of liquid hydrogen done on a GM/Opel Zafira. The large hose contains the insulated $\mathrm{LH}_{2}$ supply and the gas return lines. The small hose carries the lines for Helium purge gas and Nitrogen gas for the pneumatic support functions.

An engaged manual dispenser is shown on a GM/Opel FC car in Fig. 11. Automatically operated refuelling of liquid hydrogen vehicles is also possible. The first ever liquid hydrogen fuelling station using a robot system is located in Munich (Germany) at the airport ${ }^{5)}$. When a car is entering the filling lane, sensors detect the vehicle type and a robot is refuelling the vehicle.

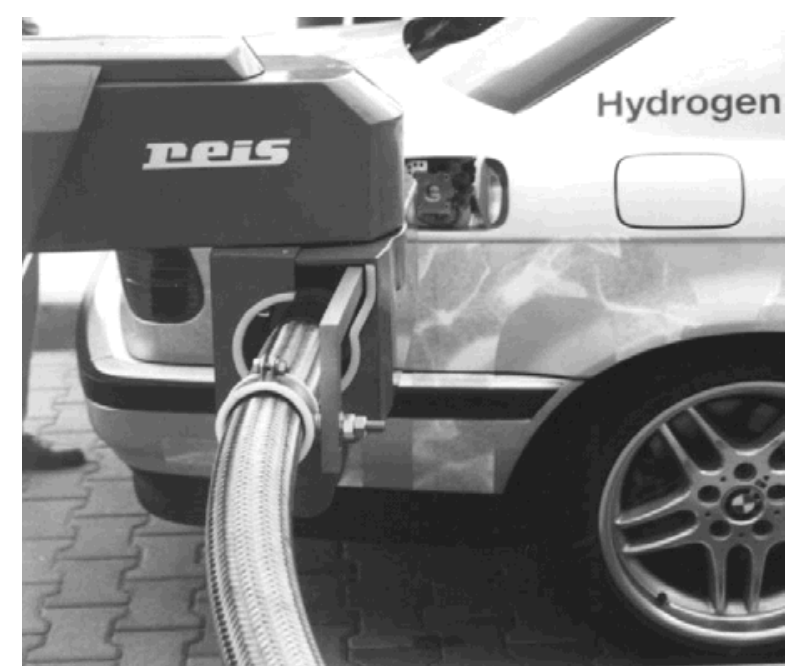

Fig. 12 Automatically operated refuelling of liquid hydrogen done on a BMW Seven Series. The first ever liquid hydrogen fuelling station using a robot system is located at Munich airport ${ }^{5)}$. When a car enters the filling lane, sensors detect the vehicle type and a robot refills the tank. Every step, beginning with opening the lid, engaging the dispenser, purging, opening the valves, pushing the cold finger, donating the $\mathrm{LH}_{2}$, closing the valves, disengaging and finally closing the lid is done automatically. A display shows the amount of hydrogen taken and after having paid with credit card the customer gets a printed receipt.
Every step, beginning with opening the lid, engaging the dispenser, purging with Helium, opening the valves, pushing the cold finger, supplying the liquid hydrogen, closing the valves, disengaging and finally closing the lid is done automatically. Amounts of hydrogen filled in are displayed and after having paid with credit card the customer gets a printed receipt, see also Fig 12.

If the tank of the vehicle is already cooled down by a previous fill, a manually performed refill takes less than five minutes. GM/Opel have demonstrated frequently the viability of liquid hydrogen as a fuel in their $\mathrm{FC}$ vehicles fleet since 2000. In a special event which was performed in May 2004 one FC car was sent on a marathon tour through Europe.

The general purpose of the tour was to demonstrate the viability and durability of fuel cell technology in vehicles. The tour started on the 3rd of May 2004 in Norway (Hammerfest, the northernmost town of the world) and ended in Portugal (Cabo da Roca, the westernmost place in Europe) on the 9th of June. The tour covered the following 14 European countries: Norway, Finland, Sweden, Denmark, Germany, Netherlands, Belgium, Great Britain, France, Swizerland, Austria, Italy, Spain and Portugal. A total mileage of app. 10'000 km was achieved without any system failures. It is worth mentioning, that during each leg of the tour, the car was driven by motor journalists who could have documented any incident through their publications.

The HydroGen3 FC vehicle was refuelled with liquid hydrogen using a mobile refuelling station. A truck loaded with two cryo containers each filled with 1000 litres of liquid hydrogen accompanied the vehicle along the entire tour, see Fig. 13.

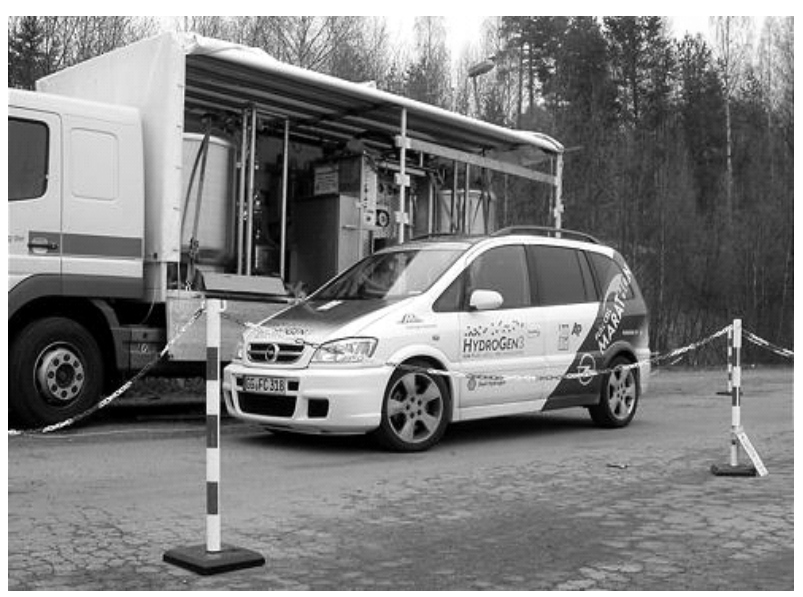

Fig. 13 GM/Opel's HydroGen3 FC vehicle is fuelled with liquid hydrogen by a mobile refuelling station during the marathon tour through Europe. A truck loaded with two cryo containers filled with liquid hydrogen accompanied the vehicle along the entire tour. 


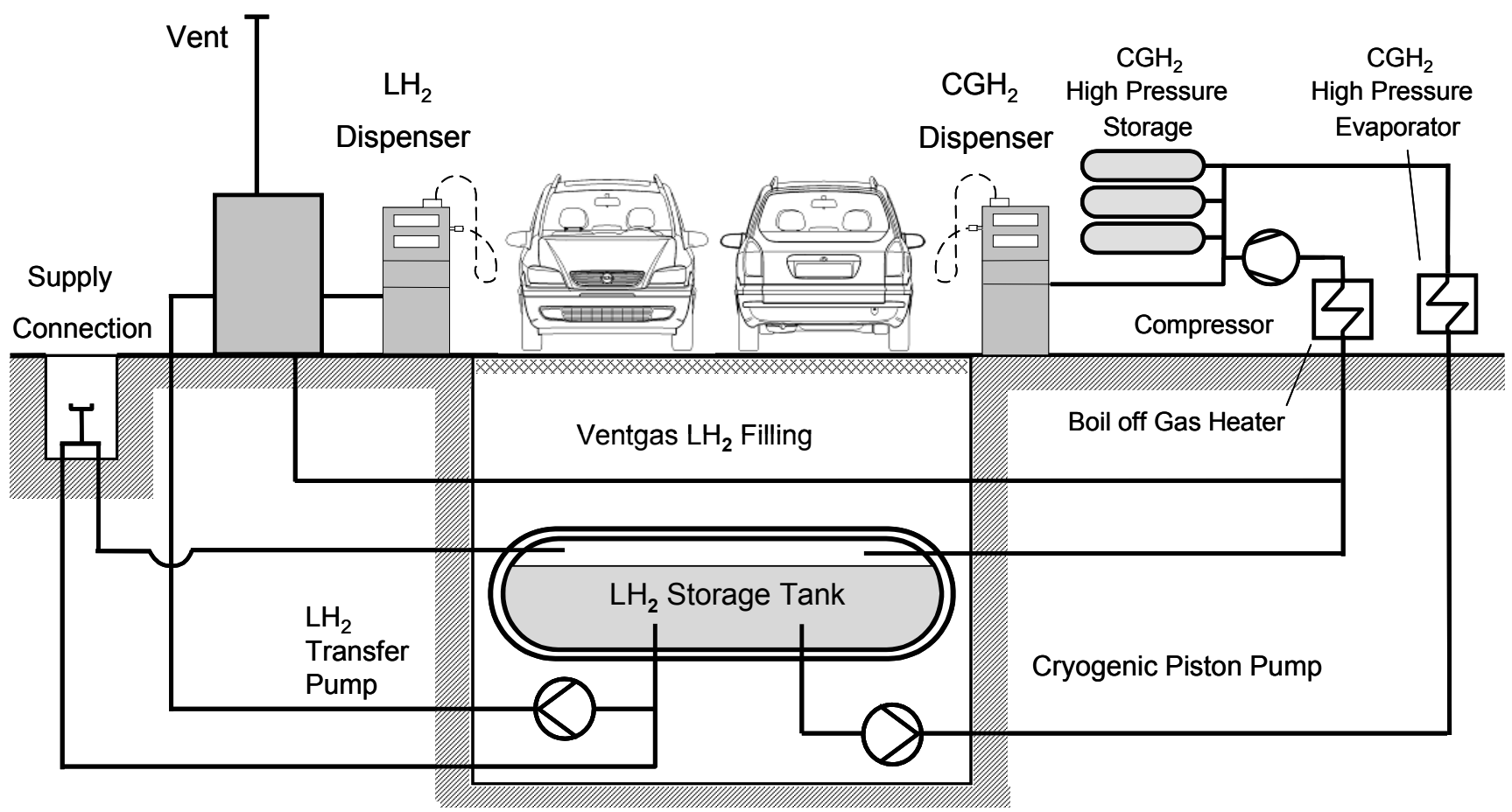

Fig. 14 Layout of a Hydrogen Filling Station for $\mathrm{LH}_{2}$ and $\mathrm{CGH}_{2}$

\section{Hydrogen Fuelling Station}

Currently, there are several scenarios under discussion to provide hydrogen at the fuelling station. Either generating hydrogen on site from natural gas by steam reforming or using electricity to produce hydrogen through water splitting. In both cases there is an additional amount of intermediate storage capacity necessary, which means that quite voluminous steel pressure cylinders with relatively low pressure are necessary. For delivering the desired pressure of 350 bars respectively 700 bars, high performance compressors have to be installed. For a fast fill to 700 bars, the spent compressed gas has to be pre-cooled by a special refrigerator device.

A simpler solution is the delivery of $\mathrm{CGH}_{2}$ to the station. This can be realized by trailers carrying steel cylinders of compressed hydrogen. The cylinders are regularly unloaded at the station; a better way is to deposit the trailer for the time of usage at the station. The hydrogen transport capacity of such $40 \mathrm{t}$ trailers is, due to the weight of the vessels, limited to $350 \mathrm{~kg}$. Recent developments have achieved $450 \mathrm{~kg}$ net $\mathrm{H}_{2}$ per trailer by using type II carbon composite hoop wrapped steel cylinders ${ }^{6)}$.

To overcome the inherent limitations of uneconomic road transport, it is advisable to transport hydrogen in liquid form. At the station, $\mathrm{LH}_{2}$ necessarily has to be stored in cryo containers either underground or above ground. A proposal for such a fuelling station serving liquid and compressed hydrogen is shown in Fig. 14.
A hydrogen fuelling station following basically the set-up of the proposal in Fig. 14 was recently opened in Berlin. It is the main fuelling station of the German Clean Energy Partnership Project ${ }^{7)}$, see Fig. 15. The inauguration

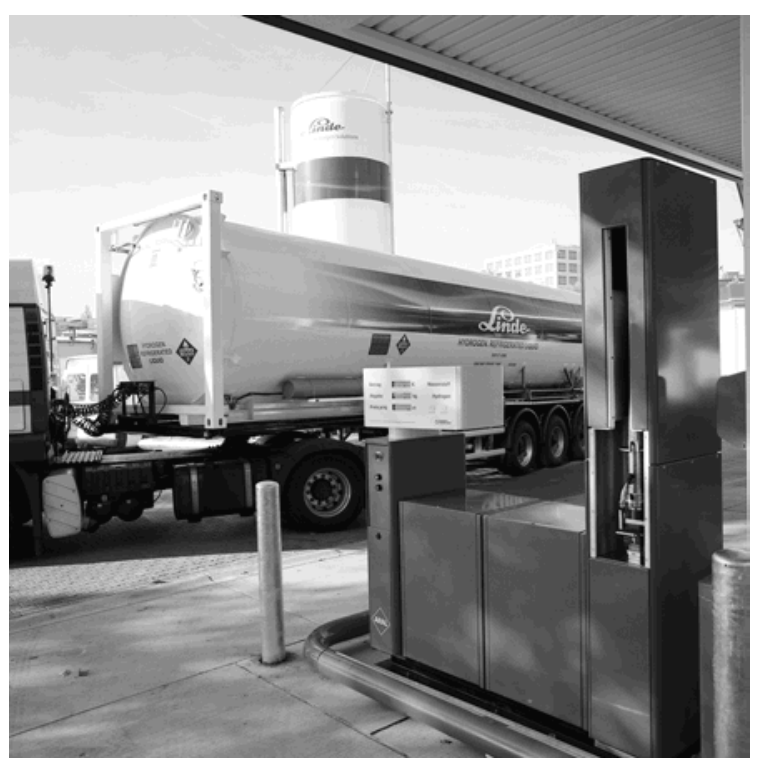

Fig. 15 CEP Hydrogen Fuelling Station in Berlin. A delivery truck for liquid hydrogen is located in front of the $\mathrm{LH}_{2}$ bulk cryo storage tank. The transport capacity of a liquid hydrogen truck is 3.5 tons. In the foreground (tall box, right hand side), a dispenser for $\mathrm{LH}_{2}$ is placed with a display for the spent amount of fuel and the price. The station also offers compressed hydrogen at 350 bars (with provisions for 700 bars) as well as gasoline and diesel on the same spot. 
was on 12th of November 2004. The station offers liquid hydrogen and compressed hydrogen at 350 bars (with provisions for 700 bars) as well as gasoline and diesel on the same spot.

For obvious reasons, a joint usage of only one main liquid hydrogen tank is preferable. The proposed layout, shown in Fig. 14, avoids any boil-off gas losses generated from the main tank and also boil-off losses resulting from handling with $\mathrm{LH}_{2}$ like filling the bulk tank from the trailer or refuelling the vehicles. The vent gas is always collected and stored in high pressure cylinders at the station.

As shown in the principle filling station layout, the liquid hydrogen dispenser section of the station is supported by a $\mathrm{LH}_{2}$ transfer pump, located below the underground liquid storage tank. The pump works under cryogenic conditions and is able to forward liquid hydrogen into the vehicle tank against the necessary tank operating pressure. For ensuring a smooth liquid flow, the pump is equipped with three pistons. The throughput of the pump achieves $50 \mathrm{l} / \mathrm{min}$, power demand is $2.2 \mathrm{~kW}$.

These types of pumps must be located lower than the liquid surface of the hydrogen, because hydrogen must flow into the pump by gravity. Any suction of the pump would immediately create an undesired gas phase which would cause malfunction. If the bulk cryo container is located above ground, the transfer pump can as well be placed above ground fulfilling this requirement. A principle layout is depicted in Fig. 16, where the additional valves, the control gauges and the dispenser are shown. A real unit is shown in Fig 17.

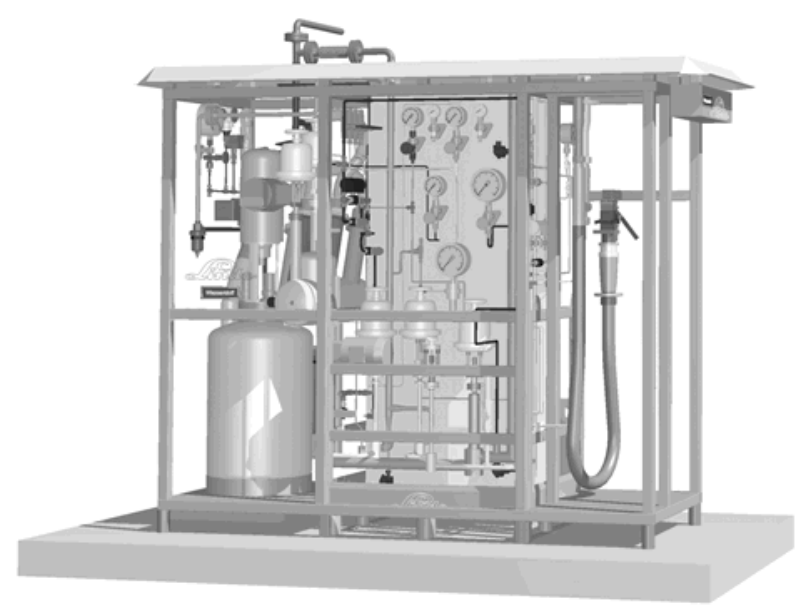

Fig. 16 Liquid hydrogen dispenser unit with valve control section and $\mathrm{LH}_{2}$ cryo transfer pump. The flexible dispenser hose is shown on the right hand side. This dispenser unit is designed in conjunction with a cryo container which is located above ground.

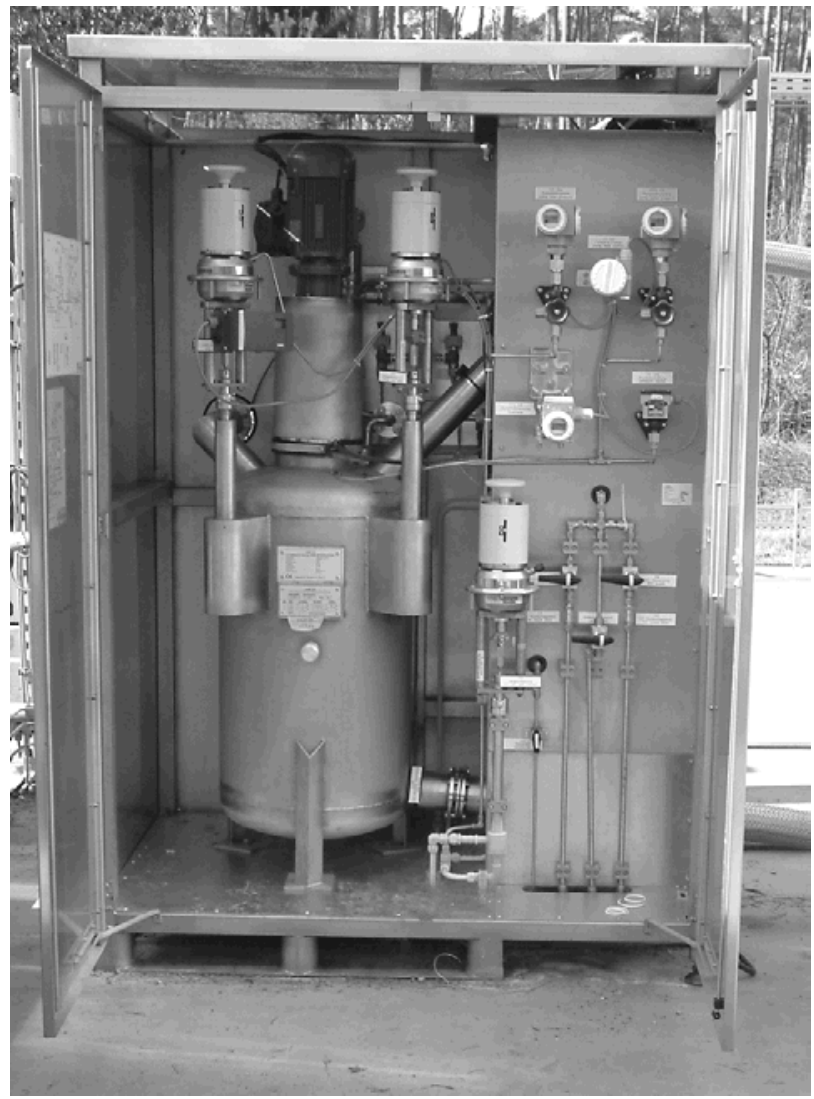

Fig. 17 Liquid hydrogen cryo transfer pump. This type of pump must be located lower than the liquid surface of the hydrogen, because hydrogen must flow into the pump by gravity. Any suction of the pump would immediately create an undesired gas phase which would cause malfunction.

A second pump, which is also working under cryogenic conditions and with the aid of gravity, serves the high pressure gas dispenser. The pump, which is shown in Fig. 14 below the $\mathrm{LH}_{2}$ storage tank on the right hand side, uses the liquid hydrogen as a source directly. The cryogenic high pressure piston pump forwards the $\mathrm{LH}_{2}$ into a high pressure evaporator, which is basically an ambient-air heat exchanger. By raising the temperature, the pressure increases to the desired pressure level. Such pumps are under development by Linde; currently they have achieved a first version with the capability to deliver 400 bars. The pump features a flow rate of five litres per minute. Higher operating pressures, up to 850 bars, are technically feasible.

It is worth mentioning, that using this kind of cryogenic high pressure pump allows the utilization of the energy spent for cooling and liquefaction as an energy source for the compression of hydrogen to the desired pressure level, see Fig. 18. 


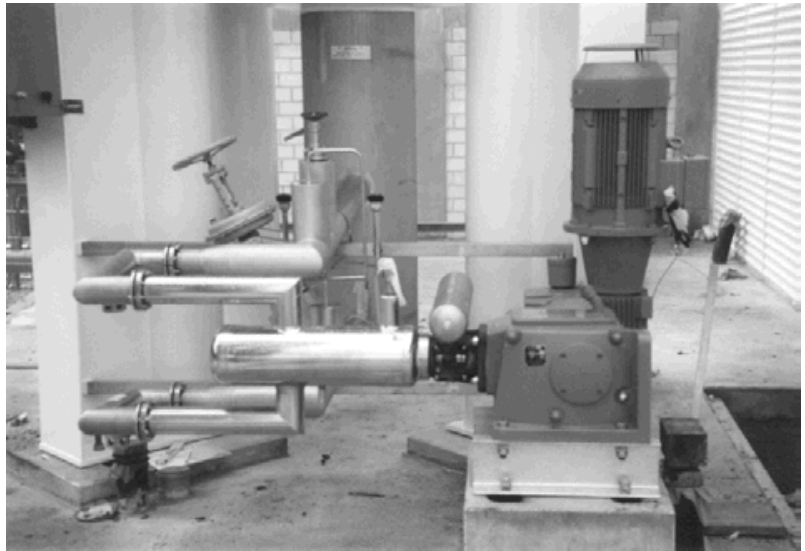

Fig. 18 Liquid hydrogen cryo transfer pump. The liquid hydrogen which flows directly from the bulk cryo container (left hand side, from above) into the pump is consequently insulated by vacuum pipes. This type of pump must be located lower than the liquid surface of the hydrogen, because hydrogen must flow into the pump driven by gravity. Any suction of the pump would immediately create undesired gas which should be avoided.

\section{Hydrogen Transportation \& Infrastructure}

Due to low demand and caused by commercial reasons, it is obvious that at the beginning of the hydrogen economy the hydrogen gas will be partly delivered by tube trailers. However, as soon as the demand raises to considerable amounts, this procedure is not longer practical. For example: currently a filling station located at a highway is selling 20 tons of gasoline and diesel fuels daily. That means, a gasoline/diesel fuel truck has to serve every day. To carry the same amount of energy ( $~ 80 \mathrm{GJ})$ in form of hydrogen, 6.5 tons have to be supplied per day. Using tube trailers of only $350 \mathrm{~kg}$ capacity, at leas 20 trucks have to be unloaded daily; this is definitely an unimaginable situation! In comparison, a liquid hydrogen trailer could fuel the same amount with 2 trips.

Hydrogen pipelines are often mentioned as the ultimate solution for the problems of gas transport. There is obviously no doubt from a technical point of view, however, due to extraordinary high investment and serious land ownership problems, it is very doubtful that such an infrastructure scenario that would cover the whole region could be built up quickly enough.

Another possibility of providing hydrogen at the filling station is the production on site. As mentioned earlier, there are two different ways under discussion: steam reforming of natural gas and electrolysis of water. The basic idea of both decentralized production methods is the usage of the existing infrastructures of the primary energy. Decentralized small reformers, however, are not seen as best performers in regard to overall efficiency.
Whatever primary energy is used, a large centralized production is strongly recommended in conjunction with a liquefier plant. Liquefying hydrogen is often criticised of being too energy consuming. In fact, presently the practical liquefaction energy demand is $3.92 \mathrm{kWh}$ per $\mathrm{kg}$, which is $32 \%$ of its caloric energy ${ }^{8,9)}$. This number is based on existing liquefier plants, see Fig. 19; new facilities will have the potential to increase their efficiency considerably. Furthermore, the expense of the liquefaction energy is to a great extend compensated by the savings in transportation.

It is mostly overlooked, that compressed hydrogen when it is transported on the road, has to be compressed on two occasions. The first time is the filling process of the transport cylinders, which is limited to 300 bars. The second time is for applying the final pressure of 700 bars to the tanks aboard the road vehicles at the station. The total energy for this two-step compression will definitely be around $20 \%$.

It is worth to mention, that liquid hydrogen inherently features always a purity of 5.0, which is perfect suited to PEM fuel cells which are mainstream in FC vehicle development.

Furthermore, a $\mathrm{LH}_{2}$ based infrastructure is a perfect pre-requisite for future ways of storing hydrogen like the so-called cryo-adsorption. This storage method is based on adsorption of hydrogen molecules on cold surfaces. The low temperature profile, which a $\mathrm{LH}_{2}$ infrastructure provides is ideal for this technology, which is currently under investigation to be utilized for hydrogen storage. Being far from a novelty status, cryo-adsorption regained a lot of attention by the discovery of new high surface materials. These compounds triggered immense interest in both academia and industry.

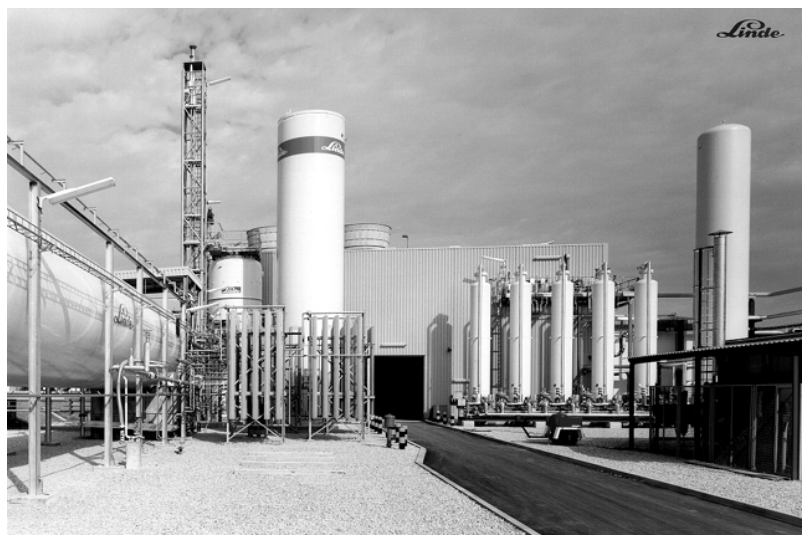

Fig. 19 Liquid hydrogen production plant of Linde Company, located in Ingolstadt, Germany. The production rate is 4.4 tons of $\mathrm{LH}_{2}$ per day. In front of the building a pressure swing gas cleaner unit is located (five tubes). The building contains the liquefaction devices like compressors, the nitrogen pre-cooling and several expansion engines. On the left hand side huge cryo storage containers are situated. 


\section{Conclusion}

There is an essential need for finding an adequate successor to the fossil fuels which offers similar qualities as a fuel for automotive application. Some serious selection processes have already selected hydrogen as the number one future energy carrier. Although hydrogen has many advantages compared to the current hydrocarbon fuels, like not being toxic or not exhausting any emissions besides water, one major drawback causes a lot of headache to the engineers. At ambient conditions, hydrogen exists only as a gas and its volumetric density is a thousand times lower than liquid gasoline. Liquefying the hydrogen gas is the most promising measure to overcome this challenge, although the energy density falls still four times short of gasoline.

The introduction of a hydrogen infrastructure built on liquid hydrogen as transport commodity, following commercial and practical considerations, seems to be the most promising way. Since liquid hydrogen as a fuel for all vehicles is probably not conceivable, a combined application of liquid hydrogen and compressed hydrogen technology is recommended.

The differentiator between both technologies is on the one hand the car performance and on the other hand the driving pattern of the owner. Because of the unavoidable boil-off losses which cryo tanks exhibit after a certain time, an appropriate usage of liquid hydrogen in vehicles is related to the duty cycle.

In Table 1, a rough split of vehicles, which divides the hydrogen storage technology users in two categories, is shown. Due to the volumetric energy density problems when using compressed hydrogen, liquid hydrogen is generally preferable for passenger cars with engine power greater than $150 \mathrm{~kW}$. Other, also smaller vehicles, which are used on a daily basis, like taxis and delivery vans, are able to use liquid hydrogen without any problems. They are not bothered at all by boil-off problems.

Larger vehicles like transit busses, coaches and trucks are predestined for liquid hydrogen as they have generally a home base and would always return to it for maintenance and refuelling. They can use liquid hydrogen in cryo tanks while the hydrogen is stored "passenger friendly" on a low pressure level.

Drivers who use their cars not on a strict everyday schedule or use it more or less randomly are better off with

Table 1 Breakdown of possible applications for $\mathrm{LH}_{2}$ and $\mathrm{CGH}_{2}$ in a future hydrogen economy

\begin{tabular}{|l|l|}
\hline \multicolumn{1}{|c|}{ Liquid Hydrogen } & Compressed Hydrogen \\
\hline & \\
Passenger Cars $>150 \mathrm{~kW}$ & Passenger Cars* $<150 \mathrm{~kW}$ \\
Taxis & \\
Delivery Vans & *and all vehicles such as \\
Transit Busses & Vans, SUVs, Light Duty Trucks \\
Coaches & which are not running on an \\
Trucks & everyday schedule and do not \\
& return to their home base daily \\
\hline
\end{tabular}

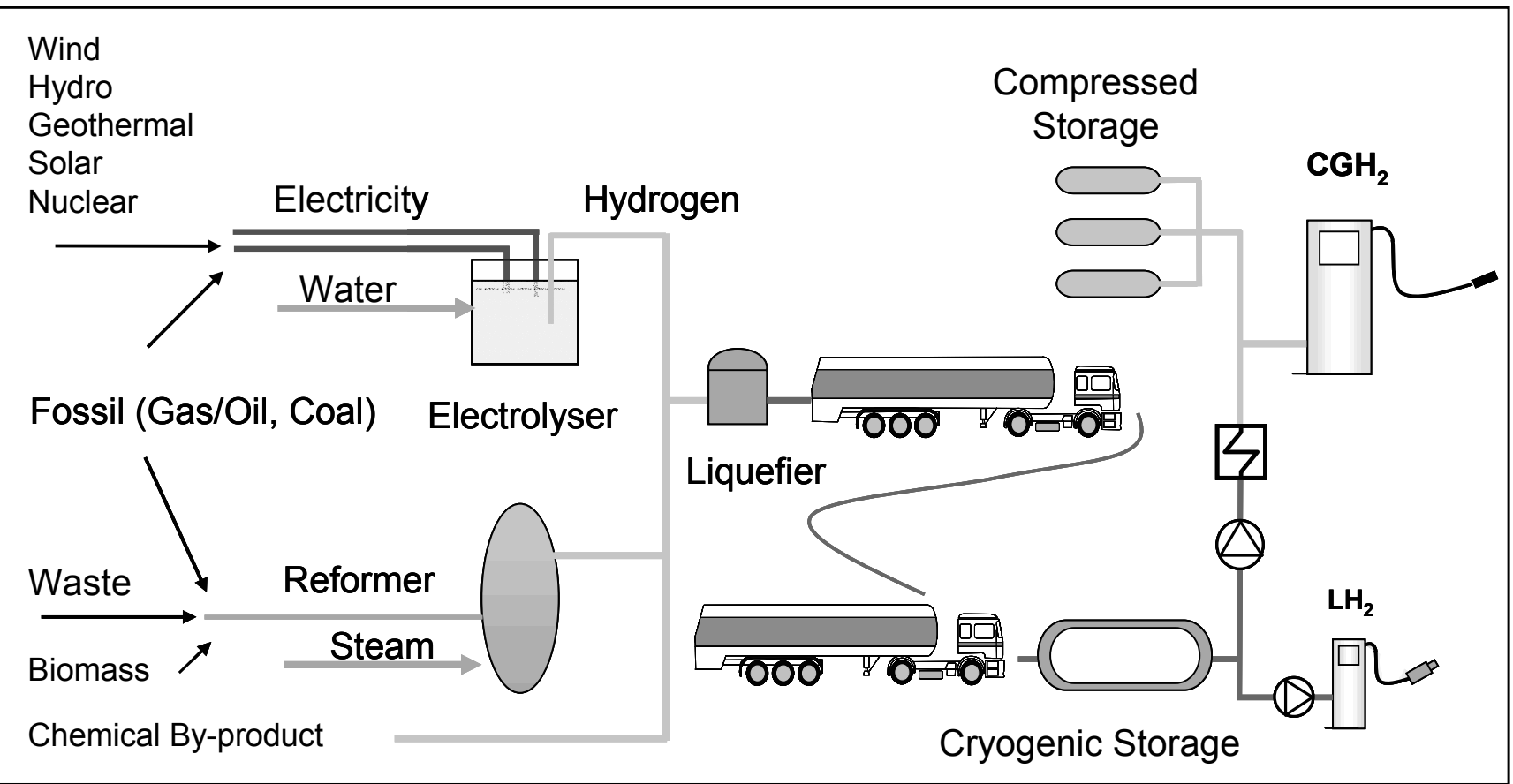

Fig. 20 Hydrogen Infrastructure based on liquid hydrogen road transport. 
compressed hydrogen. It is the large group of private car owners who cannot accept hydrogen losses at all. Presumably this group is larger than the above mentioned one, but it depends strongly on the vehicle fleet situation in each country.

Thus, in a final hydrogen infrastructure scenario we will see mainly centralized hydrogen production, based on different primary energy scenarios, see Fig. 20. Countries which are still rich on fossil fuels can use those preferably in conjunction with carbon sequestration. Other countries have the choice to utilize those renewable energies which they are best equipped with.

We will have central liquefaction plants and large-scale road transportation. The filling stations will mainly offer compressed hydrogen based on trucked-in liquid hydrogen for the large group of private car owners and also a minor fraction of liquid hydrogen for the commercial fleets and frequent drivers.

\section{References}

1) Well-to-Wheel Energy Use and Greenhouse Gas Emissions of Advanced Fuel/Vehicle Systems - North American Analysis. General Motors, Argonne Nat. Lab., BP, Exxon Mobil, and Shell, June 2001

Part 1: http://www.transportation.anl.gov/pdfs/TA/163.pdf

Part 2: http://www.transportation.anl.gov/pdfs/TA/164.pdf (accessed 9. May 2005)

2) GM Well-to-Wheels Analysis of Energy Use and Greenhouse Gas Emissions of Advanced Fuels/Vehicles Systems. A European study. LBST, September 2002.

http://www.lbst.de/gm-wtw (accessed 9. May 2005)

3) WELL-TO-WHEELS ANALYSIS OF FUTURE AUTOMOTIVE FUELS AND POWERTRAINS IN THE EUROPEAN CONTEXT, Version 1b. concawe, EUCAR, JRC, January 2004. http://ies.jrc.cec.eu.int/Download/eh/31 (accessed 9. May 2005)

4) http://www.bmwworld.com/models $/ 750 \mathrm{hl} . \mathrm{htm}$
5) Hydrogen Filling Station, Munich Airport http://www.argemuc.de (accessed 20.May 2005)

6) MCS, Mannesmann Cylinder Systems, Cylinder Tube Trailer http://www.mcs-international-gmbh.de (accessed 5. May 2005)

7) Aral Filling Station, Berlin, Messedamm, http://www.cep-berlin.de (accessed 19. May 2005)

8) C.J.J. Reijerkerk: "Hydrogen Filling Stations Commercialization", Master Thesis C.J.J. Reijerkerk, University of Hertfordshire in conjunction with Hamburg University of Applied Sciences, $14^{\text {th }}$ September 2001, Vol. I + II, Linde AG, Unterschleißheim (2001)

9) B. Valentin: "Wirtschaftlichkeitsbetrachtung einer Wasserstoff Infrastruktur für Kraftfahrzeuge," Diplomarbeit B. Valentin, Fachhochschule München, Linde AG, Unterschleißheim, Germany (2001)

Gerd ARNOLD Dr. Gerd Arnold was born in 1945, he studied physics at University of Hanover and earned his $\mathrm{PhD}$ in 1980 with a thesis on metal hydrides at the Research Centre Jülich. He joined Daimler-Benz in Stuttgart for four years developing new Diesel engines followed by an appointment by Adam Opel AG to develop Otto engines. In 1999, Dr. Gerd Arnold joined the GM fuel cell team leading the advanced hydrogen storage research.

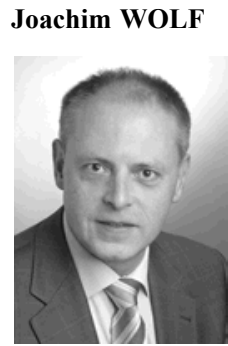

Dr. Joachim G. Wolf was born in 1951, he studied physics at University of Stuttgart and achieved his $\mathrm{PhD}$ in 1982 at Max Planck Institute for Metals Research in Stuttgart. After five years of low temperature research at MPI he joined Linde in 1987, leading several projects for space applications. In 2000 he was working for two years in Linde's headquarter on strategic corporate development. In 2003, Dr. Joachim Wolf was appointed Executive Director "Hydrogen Solutions". 